\title{
Knowledge and Attitudes Regarding Transgender and Intersex Individuals Among Medical Students and Health Care Providers of Karachi, Pakistan
}

\author{
Zaeema Ahmer ${ }^{*}$, Sana Yasir ${ }^{1}$ and Hira Tariq ${ }^{1}$ \\ 'APPNA Institute of Public Health (AIPH), Jinnah Sindh Medical University (JSMU), Karachi, Pakistan
}

\begin{abstract}
Background: Transgender and intersex individuals face numerous hurdles in accessing health facilities. Furthermore, there is no formal training for the provision of care for such a vulnerable population.

Objective: This study explores the knowledge and attitude of medical students and Healthcare Providers (HCPs) about transgender and intersex individuals in Karachi.

Methods: The cross-sectional study was conducted among medical students of a government medical college and HCPs, from August to September 2019. A structured questionnaire was used to assess the knowledge and attitude of study participants towards intersex and transgender individuals. Data were analyzed using SPSS 20.

Results: Of the 200 participants, 171 returned the complete questionnaire with a response rate of $85.5 \%$. There were $100(58.5 \%)$ females and 71(41.5\%) males, with 93(54.4\%) medical students and 78(45.6\%) HCPs. All study participants were familiar with the term transgender, while $138(80.7 \%)$ reported having heard the term intersex, whereas $35(20.5 \%)$ regarded the conditions as a mental illness. Knowledge of PMC code regarding gender orientation was significantly higher in HCPs than medical students $(41 \%$ vs $14 \%, p<0.001)$. Medical students were more in favor of corrective surgery to be performed $(61.3 \%)$ as compared to the HCPs $(43.6 \%)(p=0.02)$.

Conclusion: Even though medical students and HCPs were familiar with transgender and intersex terms yet there were different misconceptions regarding them. However, our target population was willing to learn the healthcare needs of such individuals. It is recommended that the latest guidelines regarding gender spectrum are taught in the medical curriculum.
\end{abstract}

Keywords: Intersex, transgender, knowledge \& attitude study, medical students, healthcare providers.

\section{INTRODUCTION}

Intersex is an emerging umbrella term that encompasses medically recognized conditions that result from natural variation of chromosome combination, hormone balance or internal and external body parts in a person formerly referred to as Disorders of Sexual Development (DSD) [1]. This term DSD is rejected by intersex activists all over the world as they prefer a less stigmatized term "intersex" to describe their condition. A human baby is born male, female or Intersex on the spectrum of biological sex. Recognizing that biological sex and gender are not the same is important as gender is another spectrum that talks about the personal perception of the individual's identity as a man, woman, transman, transwoman, non-binary or agender [1, 2].

In May 2018, the transgender person protection bill was passed by the parliament which ensures equal rights for transgender citizens of Pakistan and makes it legal for them to self-identify their gender [3]. It also ensures the highest attainable health as their basic human right.

*Corresponding author: Zaeema Ahmer, APPNA Institute of Public Health, Jinnah Sindh Medical University, Karachi, Pakistan;

Email: zaeema.ahmer@jsmu.edu.pk

Received: April 07, 2021; Revised: May 19, 2021; Accepted: May 21, 2021 DOI: https://doi.org/10.37184/lnjpc.2707-3521.3.4
Despite the passing of this Bill, there are no exclusive gender health clinics in Pakistan and both transgender and intersex individuals have limited resources available regarding their health. The subject of transgender and intersex health is not yet a part of the medical curriculum [3]. Medical students are not trained in handling intersex bodies or transitioning bodies [4]. Endocrinologists and paediatric surgeons treat many medically recognized intersex conditions by "fixing" them in the binary norm of male or female gender by performing cosmetic surgeries on intersex children which are considered a human rights violation by United Nations [5]. Conversion therapies performed on transitioning individuals by psychologists are also condemned by human rights activists and organizations globally. The latest DSM 5 of APA has removed gender identity disorder as a mental illness [6].

A recent study in the UK shows that medical professionals are dealing inadequately with transgender and intersex people because of their lack of training [7]. Another study conducted in the USA shows that there is a dire need for training to increase HCP's knowledge and competency regarding transgender and intersex people's health [8].

Due to the existing taboo and stigma, transgender and intersex people face hurdles in getting necessary medical 
treatment [9]. This vulnerable community experiences a high disease burden especially with regards to substance abuse, sexually transmitted diseases (STDs), HIV and mental health issues [10]. Discrimination at the hands of HCPs and undergraduate medical students striving to become doctors only exacerbates these adverse health outcomes [11]. Hence increased knowledge and empathic attitudes of HCPs and future doctors can improve the health outcomes of this invisible and marginalized population. There is no local research to show if HCPs or medical students have enough knowledge on the subject or if they empathize with transgender and intersex people. The objective of this study is to determine the existing knowledge and attitude of HCPs in various clinical and non-clinical settings and medical students regarding transgender and intersex individuals in urban Karachi.

\section{SUBJECTS AND METHODS}

A cross-sectional study was conducted between August to September 2019 among medical students at Jinnah Sindh Medical University and various HCPs in clinical and non-clinical settings. Formal ethical clearance was sought by the Institutional Review Board of Jinnah Sindh Medical University.

Male and female medical and HCPs, who were practicing in different capacities for the past five or more years like OBGYN, urologists, endocrinologists, family physicians, public health specialists, etc. were inducted through non-probability convenience sampling after getting their informed consent. The medical students were approached in their medical university in their college premises during their free time. The HCPs were pre-registered to a series of workshops, arranged by Jinnah Sindh Medical University, highlighting the issues of such individuals. The selfadministered questionnaire was distributed before the start of the workshop and was collected after 20 minutes, once the participants filled out the survey.

The sample size was estimated from the software Open Epi [12]. Since there was no previous survey conducted regarding the knowledge of students \& HCPs about the transgender \& intersex population, an anticipated population proportion of $50 \%$, confidence level of $95 \%$ and bound on the error of $10 \%$ was assumed which resulted in a sample size of 97 observations.

A structured questionnaire was developed based on scientific literature, which was used to assess the knowledge and attitude of medical students and HCPs practicing in various clinical and non-clinical settings, regarding transgender \& intersex individuals $[13,14]$. The questionnaire contained ten items on knowledge and attitude with selected demographic variables like age, occupation and education. Items related to knowledge regarding transgender \& intersex individuals enquired about their anatomical conditions, their knowledge on healthcare providers dealing with this vulnerable population and the PMC code of ethics for them. Attitudes were assessed by items pertaining to the surgical correction of these individuals done at an early stage, whether it was considered a criminal offense to be the said conditions and whether this was considered a mental health condition according to the respondents. The answers to the responses were assessed as a 'Yes/No' categorical variable.

Face Validity of the tool was done by public health experts whereas the reliability score of 0.909 revealed a very good internal consistency with our study population as well. After pre-testing on $10 \%$ of the similar sample, data were collected, cleaned for missing variables and cross-validated by random checking.

Data was entered in SPSS version 20, where categorical variables were summarized by frequencies and percentages. Chi-square test was used to find the significant difference between knowledge and attitude of both categories of the study participants. A p-value of $\leq 0.05$ indicated statistical significance.

\section{RESULTS}

A total of 200 participants were enrolled in the study, out of which 171 returned the complete questionnaire with a response rate of $85.5 \%$. More than half of the study participants $(n=100,58.5 \%)$ were females. $78(45.6 \%)$ were healthcare providers and $93(54.4 \%)$ were medical students. The mean age of medical students was $22.4 \pm$ 1.1 years and the mean age of healthcare providers was $37.6 \pm 1.9$ years. The majority of the participants, reported having heard the term intersex $(n=138$, $80.7 \%$ ), whereas all study participants were familiar with the term transgender. More than one-third of the participants thought it was the same medical condition $(n=68,39.8 \%)$ and more than half of them believed they had both male and female body parts ( $n=99,57.9 \%)$.

A small proportion, considered transgender and intersex individuals to have mental health problems $(n=35$, $20.5 \%$ ) and $22(12.9 \%)$ even thought of it as a criminal offense. The majority $122(71.3 \%)$ of the study participants stated that trained HCPs are not present to treat transgender and intersex persons. Many, of the participants, were not aware of the PMC code about gender orientation $(n=126,73.7 \%)$. More than half were of the opinion that corrective surgery should be performed on such individuals ( $n=91,53.2 \%)$ and nearly all participants wanted basic knowledge regarding transgender and intersex to be part of the medical curriculum ( $n=161,94.2 \%)$. 
When knowledge was compared between two groups of study participants, HCPs were found to have significantly more knowledge about the PMC code of ethics as compared to medical students with a p-value of $<0.001$. When attitude was compared between healthcare providers and medical students, it was observed that medical students were more in favour of corrective surgery to be performed as compared to the HCPs $(61.3 \%$ versus $43.6 \%, p=0.021)$ (Table 1$)$.
The study revealed that despite a majority of the study participants being aware of the terms transgender and intersex, more than one-third still did not know the difference between the two, with a big proportion thinking it's the same medical condition. More than half believed they have both male and female body parts which indicated the lack of knowledge of both medical students and HCPs. This is in line with the findings of Boston University medical students, whereby three out of four

Table 1: Association of different independent factors among medical students and the Healthcare Providers.

\begin{tabular}{|c|c|c|c|c|}
\hline $\begin{array}{l}\text { Knowledge and Attitude Towards } \\
\text { Transgender and Intersex Individuals }\end{array}$ & Yes/No & $\begin{array}{l}\text { Healthcare Providers } \\
n(\%)\end{array}$ & $\begin{array}{l}\text { Medical Students } \\
\mathrm{n}(\%)\end{array}$ & p-value \\
\hline \multicolumn{5}{|l|}{ Knowledge } \\
\hline Have heard the term Intersex & No & $11(14.1)$ & $22(23.7)$ & 0.115 \\
\hline Have heard the term Transgender & Yes & $78(100)$ & $93(100)$ & - \\
\hline \multirow{2}{*}{$\begin{array}{l}\text { There are trained healthcare providers for transgender } \\
\text { and intersex }\end{array}$} & Yes & $17(21.8)$ & $32(34.4)$ & \multirow[t]{2}{*}{0.069} \\
\hline & No & $61(78.2)$ & $61(65.6)$ & \\
\hline \multirow{2}{*}{$\begin{array}{l}\text { There should be basic knowledge in the medical } \\
\text { curriculum }\end{array}$} & Yes & $72(92.3)$ & $89(95.7)$ & \multirow{2}{*}{0.347} \\
\hline & No & $6(7.7)$ & $4(4.3)$ & \\
\hline \multirow{2}{*}{$\begin{array}{l}\text { Intersex and transgender individuals have mental health } \\
\text { problems }\end{array}$} & Yes & $17(21.8)$ & $18(19.4)$ & \multirow{2}{*}{0.694} \\
\hline & No & $61(78.2)$ & $75(80.6)$ & \\
\hline \multirow{2}{*}{ It is a criminal offense to be transgender and intersex } & Yes & $10(12.8)$ & $12(12.9)$ & \multirow[t]{2}{*}{0.987} \\
\hline & No & $68(87.2)$ & $81(87.1)$ & \\
\hline \multirow[t]{2}{*}{ Corrective surgery should take place } & Yes & $34(43.6)$ & $57(61.3)$ & \multirow[t]{2}{*}{ *0.021 } \\
\hline & No & $44(56.4)$ & $36(38.7)$ & \\
\hline
\end{tabular}

${ }^{*}$ p-value $<0.05$

\section{DISCUSSION}

In the current study, we explored the knowledge and attitudes of both medical students and HCPs regarding transgender and intersex individuals. All study participants had heard the term transgender and the majority were aware of the term intersex. This visibility has mainly been achieved through media, which focuses on their social and health issues. Recent reforms like Transgender Protection Act 2018 in Pakistan, have given them rights for recognition and also to basic health [3]. This is similar to the United States, where media portrayals of high profile transgender individuals and legal battles have given them recognition, with reforms in place in their health system to address discrimination [11]. However, the matter of knowledge is still under debate among medical students and HCPs. classes demonstrated lower knowledge about transgender health [4]. A study in a UK University conducted on medical students of all years showed similar results in which the majority of the students reported a lack of knowledge regarding such individuals [7].

A few study participants regarded it as a criminal offense if an individual self-identifies as transgender or intersex. This was found in a study done on exploring hate crimes and violence faced by transgender individuals where it was reported that transgender individuals were believed to have committed a crime by not living within the rules of society [15].

The majority of our study population was of the opinion that there are no trained HCPS to take care of such individuals. A survey conducted on the knowledge and 
practice of gynaecologists in India also concluded that among the respondents, $80 \%$ had received no training about caring for transgender patients during their residency and only $29 \%$ to $35.3 \%$ were comfortable in caring for them [16]. Another study in the United States conducted on practicing's nurses' knowledge concluded that they had low efficacy and confidence when treating a transgender person which in turn implies a gap in nurse practitioner education [17]. This is also congruent with a Canadian study where many physicians and transgender stated the lack of knowledge among the physicians themselves (18). Nearly all of the participants believed that basic knowledge about transgender and intersex individuals should be part of the medical curriculum [18]. Another study conducted in osteopathic and allopathic medical schools in both Canada and the US reported that the median time allocated to teaching (Lesbian, Gay, Bi-sexual, Transgender) LGBT content in the entire medical curriculum was only 5 hours and there was no teaching during preclinical and clinical years as well [19]. The article further suggested incorporating rigorous material and strategies in the curriculum for addressing gender variation [19].

One-fifth of the participants also claimed that transgender and intersex individuals have mental health problems. This is in line with a study, which provides an overview for the psychiatrists and states that transgender individuals do opt for mental health treatment intermittently, while undergoing gender transition, or contemplating it [20].

In our study, a significant association was observed in which medical students were more in favour of corrective surgery as compared to HCPs $(p=0.020)$. This might be due to inadequate knowledge of medical students regarding corrective surgeries, as they are discouraged by intersex activists globally. Surgeries have their implications and raise ethical concerns about patient decision-making [21]. As in the Pakistani society the (intersexed/ hermaphrodites), eunuchs, transvestites, bisexuals or homosexuals are all considered as transgender individuals or the third gender and are known as 'Hijra or Khawaaja Sara' in Urdu. Their constant exposure to traumatic events such as rejection and discrimination by the society as well as their biological family members, sexual, physical as well as mental abuse beginning in childhood, housing discrimination in their adult lives and discriminatory attitude from health care service providers have made their survival a constant battle [22]. The religious and socio-cultural environment in our country has secluded trans-genders and added to the stigma associated with them. Most of them cannot avail of academic and employment opportunities and hence are made to work as beggars or sex workers. Social relations in Pakistan have traditionally been centred on the family, transsexual people often fear that their transsexualism would disrupt these important relationships [23]. However, if the parents are guided properly by the healthcare professionals, a lot of stigmatization can be prevented for these vulnerable individuals.

The strength of the study includes focusing on a vulnerable population and clearing myths about them. However, the social taboo associated with transgender and intersex individuals [24] resulted in a non-response bias among the study participants. In addition, the enrolled sample size was not very large and the study was cross-sectional. Therefore we cannot report the changes in the knowledge and attitude of medical students and HCPs in the future. Also, another limitation of the study was the lack of definition provided for the terms transgender and intersex individuals to the study participants.

\section{CONCLUSION}

Even though medical students and HCPs were familiar with transgender and intersex terms yet there were different misconceptions regarding them. However, our target population was willing to learn the healthcare needs of such individuals. It is recommended that the latest guidelines regarding gender spectrum are taught in the medical curriculum.

\section{ETHICS APPROVAL}

Formal ethical clearance was sought by the Institutional Review Board of Jinnah Sindh Medical University. All procedures performed in studies involving human participants were in accordance with the ethical standards of the Helsinki declaration.

\section{CONSENT FOR PUBLICATION}

Not applicable.

\section{FUNDING}

None.

\section{CONFLICT OF INTEREST}

The authors declare no conflict of interest.

\section{ACKNOWLEDGEMENTS}

The authors wish to acknowledge Prof. Lubna Baig, Chairperson AIPH, JSMU, for permitting to conduct workshops for their study. 


\section{REFERENCES}

1. United Nations. 2015-UNFE-Report.pdf. 2015.

2. Hiort O. Formation of an open world-wide network on DSD. Proceedings of the 4th International Symposium on Disorders of Sex Development. University of Glasgow, Glasgow, UK, 2013.

3. Authority PSP, Government of the Punjab. Transgender_ Persons_Welfare_Policy. August 2018.

4. Liang JJ, Gardner IH, Walker JA, Safer JD. Observed deficiencies in medical student knowledge of transgender and intersex health. Endocr Pract 2017; 23(8): 897-906.

5. Korpaisarn S, Safer JD. Gaps in transgender medical education among healthcare providers: A major barrier to care for transgender persons. Rev Endocr Metab Disord 2018; 19(3): $271-5$.

6. Diamond M, Garland J. Evidence regarding cosmetic and medically unnecessary surgery on infants. J Pediatr Urol 2014; 10(1): 2-6.

7. Parameshwaran V, Cockbain BC, Hillyard M, Price JR. Is the lack of specific lesbian, gay, bisexual, transgender and queer/ questioning (LGBTQ) health care education in medical school a cause for concern? Evidence from a survey of knowledge and practice among UK medical students. J Homosex 2017; 64(3): 367-81.

8. Nowaskie DZ, Sowinski JS. Primary care providers' attitudes, practices, and knowledge in treating LGBTQ communities. J Homosex 2019; 66: 1927-47.

9. Stroumsa D, Shires DA, Richardson CR, Jaffee KD, Woodford MR. Transphobia rather than education predicts provider knowledge of transgender health care. Med Educ 2019; 53(4): 398-407.

10. Herbst JH, Jacobs ED, Finlayson TJ, McKleroy VS, Neumann MS, Crepaz N, et al. Estimating HIV prevalence and risk behaviors of transgender persons in the United States: a systematic review. AIDS Behav 2008; 12(1): 1-17.

11. Dubin SN, Nolan IT, Streed CG Jr, Greene RE, Radix AE, Morrison SD. Transgender health care: improving medical students' and residents' training and awareness. Adv Med Educ Pract 2018; 9: 377-91.
12. Sullivan KM, Dean A, Soe MM. On academics: OpenEpi: a web-based epidemiologic and statistical calculator for public health. Public Health Rep 2009; 124(3): 471-4.

13. Walch SE, Ngamake ST, Francisco J, Stitt RL, Shingler KA. The attitudes toward transgendered individuals scale: Psychometric properties. Arch Sex Behav 2012; 41(5): 1283-91.

14. Billard TJ. Attitudes toward transgender men and women: Development and validation of a new measure. Front Psychol 2018; 9: 387.

15. Witten T, Eyler A. Hate crimes against the transgendered: An invisible problem. Peace Rev 1999; 11(3): 461-8.

16. Unger CA. Care of the transgender patient: a survey of gynecologists' current knowledge and practice. J Women's Health 2015; 24(2): 114-8.

17. Levesque PJ. Nurse practitioners knowledge, attitudes, and self-efficacy for working with transgender patients. Clin Nurs Stud 2013; 1(4): 93-100.

18. McPhail D, Rountree-James M, Whetter I. Addressing gaps in physician knowledge regarding transgender health and healthcare through medical education. Can Med Educ J 2016; 7(2): e70.

19. Obedin-Maliver J, Goldsmith ES, Stewart L, White W, Tran E, Brenman S, et al. Lesbian, gay, bisexual, and transgender-related content in undergraduate medical education. JAMA 2011; 306(9): 971-7.

20. Barnett $C$. Opioid free anesthesia. A gender reassignment case report. Anesth E J 2019; 7: 13-4.

21. Bettcher TM. Intersexuality, transgender, and transsexuality. In: Disch L, Hawkesworth M, Eds. The Oxford handbook of feminist theory. Oxford: OUP 2015: pp. 407.

22. Akhtar M, Bilour N. State of mental health among transgender individuals in Pakistan: Psychological resilience and self-esteem. Community Ment Health J 2020; 56: 626-34.

23. Saeed A, Mughal U, Farooq S. It's complicated: Socio-cultural factors and the disclosure decision of transgenders in Pakistan. $J$ Homosex 2017; 65(1): 1-39.

24. Sanyal D, Majumder A. Presentation of gender dysphoria: A perspective from Eastern India. Indian J Endocrinol Metab 2016; 20(1): 129-33. 